\title{
Hubungan Suplementasi Tablet Fe dengan Kadar Hemoglobin pada Ibu Hamil Trimester III di Puskesmas Air Dingin Kota Padang
}

Fadina Rizki ${ }^{1}$, Nur Indrawati Lipoeto ${ }^{2}$, Hirowati Ali ${ }^{3}$

\section{Abstrak}

Zat besi ( $\mathrm{Fe})$ adalah suatu mikro elemen esensial bagi tubuh yang dibutuhkan untuk pembentukan hemoglobin. Kebutuhan tubuh akan zat besi meningkat saat kehamilan terutama selama trimester II dan III. Jumlah zat besi yang di absorbsi dari makanan dan cadangan dalam tubuh biasanya tidak mencukupi kebutuhan ibu selama kehamilan sehingga suplementasi tablet Fe diperlukan agar bisa membantu mengembalikan kadar hemoglobin. Tujuan penelitian ini adalah menganalisis hubungan antara suplementasi tablet Fe dan kadar hemoglobin pada ibu hamil trimester III. Rancangan penelitian berupa studi potong lintang dan teknik pengambilan sampel dengan metode proportional random sampling. Penelitian dilakukan di wilayah kerja Puskesmas Air Dingin Kota Padang pada bulan Juni - Agustus 2015. Sampel penelitian berjumlah 66 orang yang merupakan ibu hamil trimester III yang melakukan kunjungan dan bertempat tinggal di wilayah kerja Puskesmas Air Dingin. Hasil penelitian memperlihatkan sebagian besar ibu hamil berumur antara 20-35 tahun dan berada pada fase preterm (umur kehamilan 28-33 minggu). Hasil uji statistik menggunakan uji chi-square diperoleh $p<0,05$ (nilai $p=0,000$ ), artinya terdapat hubungan yang bermakna antara suplementasi tablet Fe dengan kadar hemoglobin pada ibu hamil trimester III. Simpulan penelitian ini adalah terdapat hubungan antara suplementasi tablet Fe dan kadar hemoglobin pada ibu hamil trimester III.

Kata kunci: suplementasi tablet Fe, kadar hemoglobin, ibu hamil trimester III

\begin{abstract}
Iron (Fe) is an essential micro element for the body required for the formation of hemoglobin. The body's need for iron increase during pregnancy, especially during the second and third trimesters. During pregnancy there is an increases of blood volume and plasma. The amount of iron in absorption of food and reserves in the body are usually not sufficient to support mother during pregnancy, so iron tablet supplementation is needed in order to help restore hemoglobin levels. The objective of this study was to analyze the correlation between iron tablet supplementation and hemoglobin levels in the third trimesters pregnant women. Cross-sectional study with proportional random sampling method was done at the Puskesmas Air Dingin Padang in June-August 2015. The samples were 66 third trimesters pregnant women who visit and reside in working area of Puskesmas Air Dingin. The results showed the majority of pregnant women aged between 20-35 years old and are in the preterm phase (28-33 weeks gestation). Results os statistical test using chi-square test was obtained $p<0,05$ ( $p$ value $=0,000$ ), meaning that there is a significant correlation between iron tablet supplementation and hemoglobin levels in the third trimesters pregnant women. This study has proven that there is a correlation between iron tablet supplementation and hemoglobin levels in the third trimesters pregnant women.
\end{abstract}

Keywords: iron tablet supplementation, hemoglobin levels, third trimesters pregnant women

Affiliasi penulis : 1. Pendidikan Dokter FKUA (Fakultas Kedokteran Universitas Andalas), 2. Bagian Gizi FKUA, 3. Bagian Biokimia FKUA
Korespondensi :Fadina Rizki,Email: fadinarizki@yahoo.co.id, Telp: +6285272447261 


\section{PENDAHULUAN}

Anemia adalah penurunan kapasitas darah dalam membawa oksigen karena jumlah sel darah merah yang kurang dari normal atau penurunan konsentrasi hemoglobin yang bisa disebabkan karena penurunan produksi eritrosit atau kehilangan darah banyak. Anemia di Indonesia umumnya disebabkan oleh kekurangan zat besi sehingga lebih sering disebut anemia defisiensi besi. Salah satu kelompok yang rentan terhadap anemia defisiensi besi adalah ibu hamil. Anemia pada ibu hamil adalah kondisi dimana kadar hemoglobin berada di bawah $11 \mathrm{~g} / \mathrm{dl}$ pada trimester I dan III atau di bawah $10,5 \mathrm{~g} / \mathrm{dl}$ pada trimester II. ${ }^{1-3}$

Prevalensi anemia pada ibu hamil di Indonesia menurut Riset Kesehatan Dasar (Riskesdas) tahun 2013 sekitar 37,1\%, sedangkan di dunia menurut World Health Organization (WHO) prevalensi ibu hamil yang mengalami defisiensi besi sekitar 35-75\%. Anemia defisiensi besi lebih cenderung berlangsung di negara berkembang dan umumnya disebabkan oleh kekurangan nutrisi, infeksi dan infestasi, perdarahan dan hemoglobinopati. ${ }^{1,4,5}$

Zat besi ( $\mathrm{Fe}$ ) adalah suatu mikro elemen esensial bagi tubuh yang dibutuhkan untuk pembentukan hemoglobin dan dapat diperoleh dari berbagai sumber makanan seperti daging berwarna merah, bayam, kangkung, kacang-kacangan dan sebagainya. Kebutuhan Fe selama kehamilan kurang lebih $1000 \mathrm{mg}$, diantaranya $500 \mathrm{mg}$ dibutuhkan untuk meningkatkan massa sel darah merah, $300 \mathrm{mg}$ untuk transportasi ke fetus dalam kehamilan 12 minggu dan $200 \mathrm{mg}$ lagi untuk menggantikan cairan yang keluar dari tubuh. Kebutuhan akan Fe selama trimester I relatif sedikit sekitar $0,8 \mathrm{mg}$ sehari yang kemudian meningkat tajam selama trimester II dan III, yaitu 6,3 mg sehari. Hal ini disebabkan karena saat kehamilan terjadi peningkatan volume darah secara progresif mulai minggu ke-6 sampai ke-8 kehamilan dan mencapai puncaknya pada minggu ke-32 sampai ke34 dengan perubahan kecil setelah minggu tersebut. ${ }^{6,7}$

Selama kehamilan akan terjadi peningkatan volume plasma sehingga mengakibatkan hemodilusi atau pengenceran sel darah dan penurunan kadar hemoglobin dari $15 \mathrm{~g} / \mathrm{dl}$ menjadi $12,5 \mathrm{~g} / \mathrm{dl}$ dan pada $6 \%$ ibu hamil bisa mencapai di bawah $11 \mathrm{~g} / \mathrm{dl}$. Pada kehamilan lanjut hal ini merupakan kondisi abnormal dan biasanya berhubungan dengan defisiensi besi. Jumlat $\mathrm{Fe}$ yang diabsorbsi dari makanan dan cadangan dalam tubuh biasanya tidak mencukupi kebutuhan ibu selama kehamilan sehingga diperlukan penambahan asupan zat besi untuk membantu mengembalikan kadar hemoglobin. ${ }^{7}$

Suplementasi tablet $\mathrm{Fe}$ adalah salah satu program pencegahan dan penanggulangan anemia defisiensi besi yang paling efektif meningkatkan kadar hemoglobin pada ibu hamil dan dapat menurunkan prevalensi anemia pada ibu hamil sebesar $20-25 \%$. Program ini sudah terlaksana di Indonesia sejak tahun 1974 dan persentase ibu hamil di Sumatera Barat yang mengkonsumsi tablet $\mathrm{Fe}$ sudah mencapai $75,8 \%$. Tablet Fe mengandung 200 mg sulfat ferrosus dan $0,25 \mathrm{mg}$ asam folat yang diikat dengan laktosa. Ibu hamil dianjurkan mengkonsumsi tablet Fe minimal 90 tablet dengan dosis 1 tablet per hari berturut-turut selama 90 hari masa kehamilannya. ${ }^{4,8-10}$

Penelitian Fanny et al pada tahun 2011 menunjukkan hasil bahwa pemberian tablet Fe sesuai standar pelayanan diiringi pola makan sesuai memberikan pengaruh terhadap kadar hemoglobin pada ibu hamil. setelah pemberian tablet $\mathrm{Fe}$, sebagian besar ibu hamil $(70 \%)$ memiliki kadar hemoglobin yang normal. Penelitian Dewi pada tahun 2008 juga memberikan hasil serupa. Menurut Depkes pada tahun 2007 cakupan pemberian tablet Fe sudah mencapai angka 92,2\%, namun ternyata prevalensi anemia pada ibu hamil masih cukup tinggi. 5,10,11

Beberapa penelitian melaporkan bahwa pemberian tablet $\mathrm{Fe}$ dapat meningkatkan kadar hemoglobin serta mengurangi kejadian anemia pada ibu hamil, namun ada juga yang melaporkan bahwa pemberian tablet Fe belum mampu mengurangi angka prevalensi anemia. Hal ini menyebabkan peneliti tertarik untuk melakukan penelitian mengenai hubungan suplementasi tablet $\mathrm{Fe}$ dengan kadar hemoglobin pada ibu hamil trimester III di Puskesmas Air Dingin Kota Padang dimana prevalensi anemia ibu hamil di puskesmas ini mencapai $32,5 \%{ }^{12}$ 


\section{METODE}

Rancangan penelitian berupa studi potong lintang. Sampel penelitian adalah ibu hamil trimester III yang berada di wilayah kerja Puskesmas Air Dingin Kota Padang. Pengambilan sampel menggunakan metode konsekutif. Sampel yang memenuhi kriteria inklusi berjumlah 66 orang. Kriteria inklusi dalam penelitian ini adalah ibu hamil trimester III, bertempat tinggal di lokasi penelitian, bersedia diperiksa kadar hemoglobin, bersedia diwawancarai, mendapatkan suplementasi tablet Fe dari Puskesmas, dan status gizi baik menurut lingkar lengan atas. Kriteria eksklusi dalam penelitian ini adalah ibu hamil yang mengalami infeksi, menderita hemoglobinopati, mempunyai riwayat perdarahan dan menderita aplasia sel darah. Variabel bebas pada penelitian ini adalah suplementasi tablet $\mathrm{Fe}$, sedangkan variabel dependen adalah kadar hemoglobin. Suplementasi tablet $\mathrm{Fe}$ diperoleh dari data Puskesmas dan dengan menanyakan langsung kepada ibu hamil berapa jumlah tablet yang telah diminum, sedangkan pemeriksaan kadar hemoglobin dilakukan langsung dengan metode digital menggunakan alat hemometer digital Easy Touch. Data yang diperoleh diolah dengan aplikasi komputer kemudian data dianalisis menggunakan uji chi-square.

HASIL

Tabel 1. Karakteristik responden

\begin{tabular}{lcc}
\hline & $\mathbf{n}$ & $\%$ \\
\hline Kelompok Umur (tahun) & 1 & 1,5 \\
$<20$ & 58 & 87,9 \\
$20-35$ & 7 & 10,6 \\
$>35$ & & \\
\hline Umur Kehamilan (minggu) & 45 & 68,2 \\
$28-33$ (Preterm) & 19 & 28,8 \\
$34-37$ (Late Preterm) & 2 & 3,0 \\
$38-40$ (Aterm) & & \\
\hline
\end{tabular}

Tabel 1 memperlihatkan bahwa sebagian besar responden penelitian berumur antara 20-35 tahun. Berdasarkan umur kehamilan responden dapat dilihat bahwa lebih dari separuh responden berada pada umur kehamilan 28-33 minggu.
Tabel 2. Suplementasi tablet $\mathrm{Fe}$ dan kadar hemoglobin

\begin{tabular}{lll}
\hline & $\mathbf{n}$ & $\%$ \\
\hline Suplementasi Tablet Fe & 28 & 42,4 \\
Kurang (<90 tablet) & 38 & 57,6 \\
Cukup $(\geq 90$ tablet) & & \\
\hline Kadar Hemoglobin & 20 & 30,3 \\
Tidak Normal $(<11 \mathrm{~g} / \mathrm{dl})$ & 46 & 69,7 \\
Normal $(\geq 11 \mathrm{~g} / \mathrm{dl})$ & \\
\hline
\end{tabular}

Tabel 2 memperlihatkan distribusi frekuensi suplementasi tablet $\mathrm{Fe}$ dan kadar hemoglobin responden. Hasil ini menunjukkan bahwa lebih banyak responden yang mendapatkan suplementasi dan mengonsumsi tablet $\mathrm{Fe}$ dengan cukup. Lebih dari separuh responden memiliki kadar hemoglobin normal.

Tabel 3. Hubungan suplementasi tablet Fe dengan kadar hemoglobin

\begin{tabular}{cccccc}
\hline \multirow{2}{*}{$\begin{array}{c}\text { Suplementasi } \\
\text { Tablet Fe }\end{array}$} & \multicolumn{4}{c}{ Kadar Hemoglobin } & \multirow{2}{*}{ Tidak Normal } \\
\cline { 2 - 4 } & $\mathbf{n}$ & $\%$ & $\mathbf{n}$ & $\%$ & \\
\hline Kurang & 20 & 71,4 & 8 & 28,6 & 0,000 \\
Cukup & 0 & 0 & 38 & 100 & \\
\hline
\end{tabular}

Tabel 3 memperlihatkan bahwa terdapat hubungan yang bermakna antara suplementasi tablet Fe dengan kadar hemoglobin pada ibu hamil trimester III $(p<0,05)$.

\section{PEMBAHASAN}

Sebagian besar ibu hamil yang menjadi responden pada penelitian ini berumur antara 20-35 tahun. Berdasarkan kepustakaan sebagian besar responden termasuk dalam kategori usia reproduksi sehat dan berisiko rendah dalam kehamilan. Semakin muda dan semakin tua umur seorang ibu yang sedang hamil, akan berpengaruh terhadap kebutuhan gizi yang diperlukan. Hal ini juga akan meningkatkan risiko-risiko yang dapat terjadi pada ibu hamil nantinya termasuk anemia defisiensi pada ibu hamil. ${ }^{13,14}$

Penelitian yang dilakukan oleh Puspitaningrum et al. pada tahun 2013 juga memberikan hasil serupa dimana sebagian besar ibu hamil berumur antara 20- 
35 tahun. Penelitian yang dilakukan oleh Fanny et al. pada tahun 2011 juga mendapatkan hasil ibu hamil terbanyak berumur antara 20-30 tahun. ${ }^{5,15}$

Hasil penelitian ini (Tabel 2) memperlihatkan bahwa lebih banyak ibu hamil yang mendapatkan suplementasi tablet $\mathrm{Fe}$ dengan cukup dan memiliki kadar hemoglobin normal. Hasil ini sejalan dengan penelitian yang dilakukan oleh Fanny et al. pada tahun 2011 tentang pengaruh pemberian tablet Fe terhadap kadar hemoglobin ibu hamil di Puskesmas Tamamaung, dimana sebagian besar ibu hamil mengkonsumsi tablet $\mathrm{Fe}$ dengan cukup dan memiliki kadar hemoglobin normal. ${ }^{5}$

Uji kemaknaan yang dilakukan diperoleh hasil bahwa terdapat hubungan yang bermakna antara suplementasi tablet $\mathrm{Fe}$ dengan kadar hemoglobin pada ibu hamil trimester III di Puskesmas Air Dingin Kota Padang. Hasil ini sejalan dengan penelitian yang dilakukan oleh Fanny et al pada tahun 2011, yang memperlihatkan bahwa pemberian tablet $\mathrm{Fe}$ sesuai dengan standar pelayanan dan diiringi pola makan yang baik akan memberikan pengaruh terhadap kadar hemoglobin ibu hamil yaitu berkurangnya jumlah ibu hamil yang mengalamai anemia. Penelitian yang dilakukan oleh Puspitaningrum et al pada tahun 2011 juga menunjukkan hasil bahwa pemberian tablet $\mathrm{Fe}$ efektif untuk meningkatkan kadar hemoglobin dan dapat menurunkan angka kejadian anemia. ${ }^{5,15}$

Penelitian ini sejalan dengan program pemerintah dalam upaya penanggulangan anemia gizi besi melalui pemberian tablet Fe kepada ibu hamil yang diberikan minimal 90 tablet dengan dosis 1 tablet per hari selama kehamilan. Sesuai dengan teori diharapkan kadar hemoglobin dapat normal pada ibu hamil yang mengkonsumsi tablet $\mathrm{Fe}$, karena kebutuhan zat besi pada trimester III kehamilan tidak dapat dipenuhi hanya dari makanan saja. Sehingga pemenuhan kecukupan zat besi dianjurkan dipenuhi melalui suplementasi. ${ }^{10}$

Kebutuhan ibu hamil akan $\mathrm{Fe}$ meningkat terutama selama trimester II dan III disebabkan saat kehamilan terjadi peningkatan volume darah dan volume plasma. Hal ini akan menyebabkan terjadinya hemodilusi atau pengenceran sel darah dan penurunan kadar hemoglobin. Jumlah zat besi yang diabsorbsi dari makanan dan cadangan dalam tubuh biasanya tidak mencukupi kebutuhan ibu selama kehamilan sehingga diperlukan penambahan asupan zat besi melalui suplementasi tablet $\mathrm{Fe}$ untuk membantu mengembalikan kadar hemoglobin pada ibu hamil. ${ }^{7}$

\section{SIMPULAN}

Terdapat hubungan yang bermakna antara suplementasi tablet $\mathrm{Fe}$ dan kadar hemoglobin pada ibu hamil trimester III.

\section{DAFTAR PUSTAKA}

1. Oliver E, Olufunto K. Management of anaemia in pregnancy. Dalam: Donald, S. Edisi Anemia. Shanghai: Intechopen; 2012.

2. Ojofeitimi EO, Ogunjuyigbe $P O$, Sanusi RA, Orji EO, Akinlo A, Liasu SA, et al. Poor dietary intake of energy and retinol among pregnant women, implications for pregnancy outcome in Southwest Nigeria. Pak J Nutr. 2008;7(3):480-4.

3. Cunningham FG, Gant FG, Leveno KJ, Bloom S, Hauth J. Obstetri Williams. Edisi ke-23. Jakarta: EGC;2009.

4. Riskesdas. Laporan hasil Riset Kesehatan Dasar (Riskesdas) tahun 2013. Jakarta: Badan Penelitian dan Pengembangan Kesehatan Kementerian Kesehatan RI; 2013.

5. Fanny L, Mustamin, Theresia DKB, Kartini S. Pengaruh pemberian tablet Fe terhadap kadar hemoglobin ibu hamil di Puskesmas Tamamaung tahun 2011. Media Gizi Pangan. 2012;13(1):7-11.

6. Yusnaini. Pengaruh konsumsi jambu biji (Psidium guajava. $L$ ) terhadap perubahan kadar hemoglobin pada ibu hamil anemia yang mendapat suplementasi tablet $\mathrm{Fe}$ (skripsi). Semarang: Universitas Diponegoro; 2014.

7. Prawirohardjo S. IImu Kebidanan. Edisi ke-4. Jakarta: PT Bina Pustaka Sarwono Prawirohardjo; 2010.

8. Suartika I. Prevalensi anemia pada ibu hamil di Puskesmas Bualemo Sulawesi Tengah. Cermin Dunia Kedokteran. 2008;124:44-5. 
9. Purwaningsih S. Analisis faktor yang mempengaruhi ketidakpatuhan ibu hamil dalam megonsumsi tablet Fe. JIK. 2006;01:02.

10. Dewi RC. Pengaruh suplementasi tablet tambah darah (TTD), seng dan vitamin A terhadap kadar hemoglobin ibu hamil. MKM. 2008;3(1):12-9.

11. Depkes RI. Profil kesehatan Indonesia 2009. Jakarta: Kementerian Kesehatan Rl; 2010.

12. Dinas Kesehatan Kota Padang. Cakupan bumil anemia. Padang: DKK; 2012.
13. Manuaba IAC, Manuaba IBGF. IImu kebidanan, penyakit kandungan, dan KB. Jakarta: EGC; 2010.

14. Kristiyanasari W. Gizi ibu hamil. Yogyakarta: Nurha Medika; 2010.

15. Puspitaningrum D, Damayanti FN, Mustika DN. Efektivitas pemberian tablet $\mathrm{Fe}$ dalam meningkatkan kadar hemoglobin pada ibu hamil trimester II dan trimester III dengan anemia di Puskesmas Bangetayu Kecamatan Genuk tahun 2013. Semarang: Universitas Muhammadiyah Semarang; 2013. 